This item was submitted to Loughborough's Research Repository by the author.

Items in Figshare are protected by copyright, with all rights reserved, unless otherwise indicated.

\title{
Determinants of customer decisions to pay utility water bills promptly
}

PLEASE CITE THE PUBLISHED VERSION

http://dx.doi.org/10.2166/wp.2009.096

\section{PUBLISHER}

(c) IWA Publishing

\section{VERSION}

AM (Accepted Manuscript)

\section{LICENCE}

CC BY-NC-ND 4.0

\section{REPOSITORY RECORD}

Mugabi, Josses, Sam Kayaga, lan K. Smout, and Cyrus Njiru. 2019. "Determinants of Customer Decisions to Pay Utility Water Bills Promptly”. figshare. https://hdl.handle.net/2134/11827. 
This item was submitted to Loughborough's Institutional Repository (https://dspace.lboro.ac.uk/) by the author and is made available under the following Creative Commons Licence conditions.

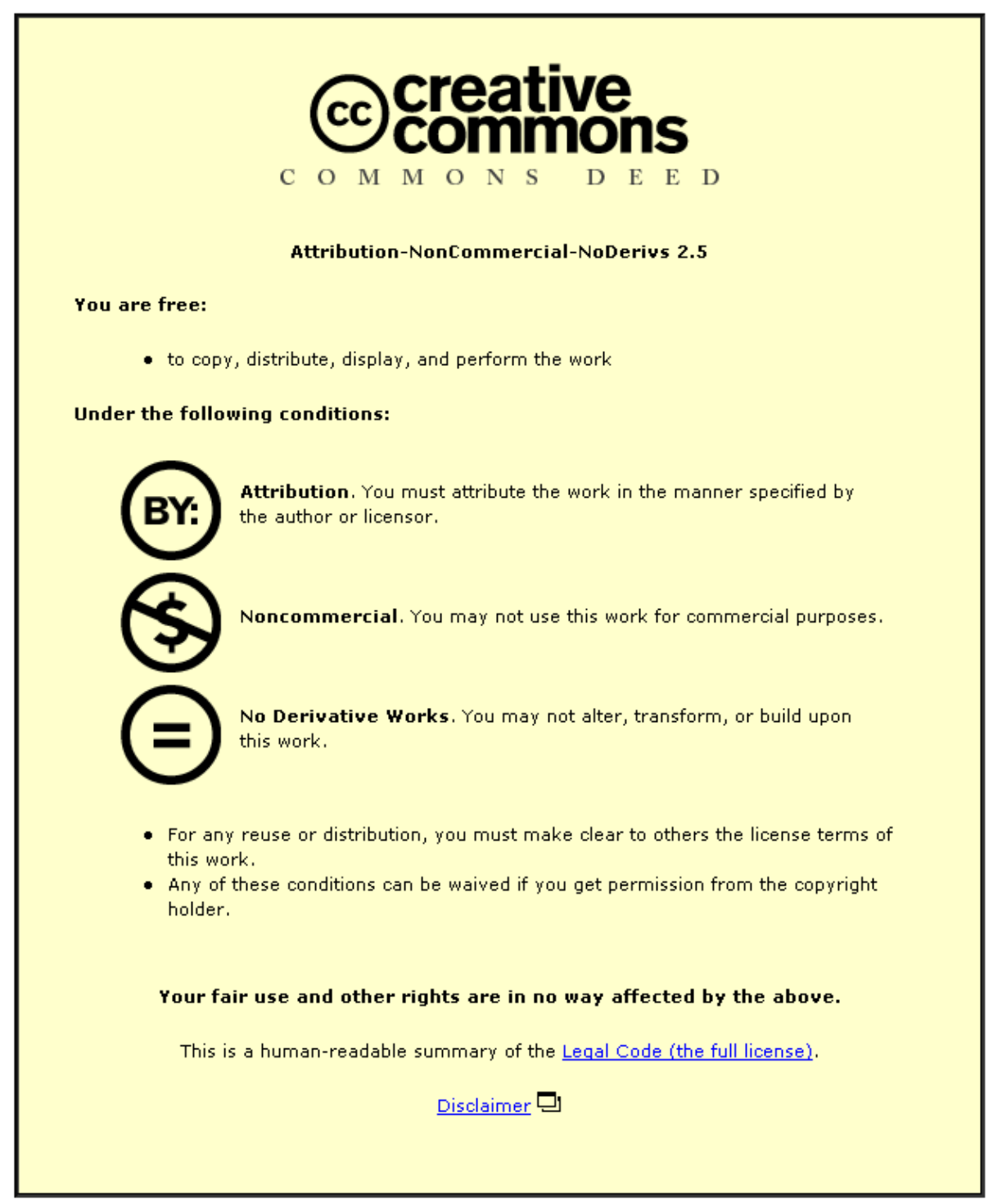

For the full text of this licence, please go to: http://creativecommons.org/licenses/by-nc-nd/2.5/ 


\section{Editorial Manager(tm) for Water Policy \\ Manuscript Draft}

Manuscript Number: WPOL-D-07-00096

Title: Determinants of Customer Decisions to Pay Utility Water Bills Promptly

Article Type: Research Paper

Corresponding Author: Dr Josses Mugabi, Ph.D

Corresponding Author's Institution: Loughborough University

First Author: Josses Mugabi, Ph.D

Order of Authors: Josses Mugabi, Ph.D; Sam Kayaga, PhD, MSc (Eng), BSc (Eng); lan Smout, MSc, BA; Cyrus Njiru, MBA, PhD, MSc (Eng), BSc (Eng 


\title{
Determinants of customer decisions to pay utility water bills promptly
}

\author{
Josses Mugabi ${ }^{\mathrm{a}^{*}}$, Sam Kayaga ${ }^{\mathrm{a}}$, lan Smout ${ }^{\mathrm{a}}$ and Cyrus Njiru ${ }^{\text {a† }}$ \\ ${ }^{a}$ Water, Engineering and Development Centre, Loughborough University, Leicestershire LE11 3TU, UK
}

\begin{abstract}
Cost recovery is a prerequisite for sustainable water service provision. For water utilities, one of the key determinants of overall cost recovery efficiency is the ability to recover payment, within a reasonable timeframe, for all the water bills sent to customers. This study used empirical data, obtained through a cross-sectional survey in eight small urban centres in Uganda to establish the determinants of customer decisions to pay utility water bills promptly. Regression analysis on the data showed that customer attitude towards prompt payment, perceived ease or difficulty of paying on time (perceived control), as well as social pressure, strongly influence intentions to pay, which in turn directly affects actual prompt bill payment behaviour. The results also show that attitudes towards prompt payment are informed by perceptions of benefits and sacrifices associated with the behaviour, while social pressure is perceived to come from family members, neighbours and the utility itself. Perceived control was found to reflect both internal and external impediments to prompt bill payment, many of which relate to service issues that are within the control of water utility managers.
\end{abstract}

Key words: Bill payment behaviour; Willingness to pay; Theory of planned behaviour; Water services; Small towns; Uganda; Developing countries

\footnotetext{
* Corresponding Author: Tel: +44-1509-223780, Fax: +44-1509-211079: Email: j.mugabi@lboro.ac.uk

$\dagger$ Present Address: African Development Bank, BP 323-1002, Tunis Belvedere, Tunisia
} 


\section{INTRODUCTION}

Field studies carried out in many countries have shown that cost recovery is a key prerequisite for sustainable water services provision (Katko, 1991). The chief means of recovering costs of service provision is through user-payments for the services provided. As a result, a key determinant of overall cost recovery efficiency is the service provider's ability to recover payment, within a reasonable timeframe, for all the bills sent to customers. However, many water utilities, especially in Africa, are unable to recover even 50 percent of their total billed amounts in any billing cycle (Kayaga, 2002). Customers fail to pay up their bills, and eventually get disconnected, leading to accumulation of huge unpaid bills.

Moreover, it appears that this problem is not unique to less-developed countries. According to a study (Accent Marketing and Research, 2003) commissioned by Ofwat (the economic regulator of the UK water industry), the levels of arrears, the amount of revenue written off, and the numbers of customers in water debt within the UK water industry have continued to rise since 1998-99 (the last full year in which disconnection of domestic water supplies was permitted for non-payment of water bills). The report estimates that the total household revenue outstanding for up to 48 months for the period 2002-03 stood at £781 million, an increase of $£ 115$ million (17\%) since 1998-99. Recent figures from Ofwat reveal that on average, UK water companies are demanding close to UK£763 million per year in revenue outstanding for up to 48 months, of which close to $£ 100$ million is eventually written off as bad debt. Needless to say, this level of arrears is unlikely to hinder water operations in a big economy like the UK, where water utilities have access to significant amounts of capital.

However, for developing countries, delayed bill payments and huge arrears can greatly undermine a utility's capacity to deliver water services. This is especially true for small water utilities that depend on a constant stream of revenue from their customers in order to survive. If a utility is not able to collect in time, all the bills that are sent out, cash flow problems set in, which in turn, impacts on the ability to cover operating expenses and extend service 
coverage. Such a situation may result in low service coverage, and potentially, poor customer service - leading to customer dissatisfaction, which may breed more 'non-payers' and trigger a cycle of poor performance. Thus, minimizing the levels of 'bad debts' and increasing the rates of revenue collection is critical for sustainable service provision.

In order to respond to problems involving delayed or irregular payments, utility managers need to determine precisely why customers might not pay their water bills in time. Yet, little empirical research exists in the literature on the factors influencing customer decisions when it comes to paying water bills in time. As part of a wider research on bill payment behaviour in urban water utilities in Uganda (Mugabi, 2007), we examined the influence of attitudinal factors on customer decisions relating to paying for water services promptly, and explored what customers perceive to be the facilitating factors and barriers to engaging in this behaviour. The current paper draws on this research to shed light on what motivates customers when it comes to paying bills promptly. Based on these insights, we identify possible ways in which water utilities could encourage prompt payment of water bills.

\section{BILL PAYMENT BEHAVIOUR IN URBAN WATER SERVICES}

Understanding domestic water demand behaviour, especially in low-income countries, has attracted a considerable amount of research attention during the past two decades. In particular, there has been an upsurge of research looking at the determinants of household demand for water services and willingness to pay (e.g. World Bank Water Demand Research Team, 1993; Perez-Pineda, 1999; Whittington et al., 2002; Hopkins et al., 2004; Gulyani et al., 2005; Casey et al., 2006; Venkatachalam, 2006; Addo-Yobo et al., 2006). However, most of these studies have been conducted within hypothetical service settings, in which willingness to pay for future service improvements is estimated. Limited research has been carried out on actual payment behaviour within an existing utility-customer relationship. This lack of interest however is not entirely surprising. Water sector practitioners are usually only 
interested in consumer behaviour studies at the front-end of new water supply projects or improvements, as input to the planning process. Once service improvements are in place, the nature of the exchange relationship between consumers and service providers has rarely been subjected to the necessary empirical scrutiny.

One study conducted in Uganda's urban water sector provides some insights regarding the factors influencing consumer behaviour with respect to paying water bills (Kayaga, 2002). Through a cross-sectional survey of 690 registered customers of a major urban water utility in Uganda, Kayaga (2002) attempted to establish the influence of customer perceptions of utility services on bill payment behaviour. The findings of this study showed that customer perceptions of service quality, service value and corporate image were strong predictors of customer satisfaction, which in turn, significantly predicted favourable customer attitudes towards paying water bills (Kayaga, 2002).

Furthermore, in an attempt to predict actual bill payment behaviour (measured as mean bill payment period), Kayaga, Franceys and Sansom (2004), modelled the effect of various attitudinal variables (i.e., service value perceptions, corporate image, customer satisfaction and, attitudes towards paying water bills). With the exception of attitudes towards paying water bills, all other variables did not have a significant influence on a customer's mean bill payment period. Moreover, the size of the variation in mean bill payment period explained by the regression model was quite small (seven percent), hence suggesting the presence of other potential influences on bill payment behaviour.

Similar studies have been conducted within the UK water industry (Herbert and Kempson, 1995; Accent Marketing and Research, 2003; UK Water Industry Research, 2004). Herbert and Kempson's (1995) pioneering study on water debt and disconnection in the UK water industry revealed a number of factors that lead water utility customers to fall behind with their bills. Using logistic regression on responses from a sample of 1,895 household heads, the authors found household incomes to be the major contributor to water debt. Attitudes to 
payment also had an independent effect, with those who felt that they must pay their water bills on time being less likely to have had arrears (Herbert and Kempson, 1995). Similar findings are reported in a study commissioned by OFWAT - the economic regulator of the UK water industry (Accent Marketing and Research, 2003). This study categorised customers with water debt into three main groups: (i) those who take the line "why should I pay" - i.e. negative attitude to paying for water generally; (ii) those who genuinely struggle financially; and (iii) poor money managers. The study recommended among others, tailoring of debt management and recovery strategies to the different customer groups.

Furthermore, UK Water Industry Research (2004) used data from 14 UK water companies to analyse the socio-economic and demographic effects on bill payment behaviour. The analysis revealed that customers with outstanding balances on their bills were more likely to have other debts and a history of indebtednesses; that a significant proportion of the water debt was associated with recent relocation; that younger generation were less likely to pay than older generations and that single people were more likely to default than couples. This study also noted that despite robust collection performance across the industry, a surprising number of customers with otherwise good payment habits were slow in paying their water bills. This suggests that the way customers react to water bills and the decisions they make regarding when to pay is not yet fully understood.

Moreover, for low-income countries, hardly any studies have focused on understanding this aspect of consumer behaviour. Although previous research has increased our knowledge of the determinants of willingness to pay, still relatively little is known on what explains variations in actual payment behaviour. Water utility managers facing difficulties in recovering bills from their existing customers would greatly benefit from research that provides a deeper understanding of the factors influencing water bill payment behaviour, in particular prompt payment. 


\section{CONCEPTUAL FRAMEWORK}

The above inadequacies in the literature bring us back to the question of what factors are critically important for motivating customer decisions about paying for water services promptly. One model that has been used extensively to understand human decision-making is the theory of reasoned action (TRA; Ajzen and Fishbein, 1980) and its extension, the theory of planned behaviour (TPB; Ajzen, 1991). These models have been used to understand and predict a wide range of human behaviours. In particular, the TPB has been used to predict health related behaviours such as condom use, smoking and exercise (e.g. Sheeran and Taylor, 1999); hygiene behaviours such as hand washing (e.g. Jenner et al., 2002), pro-environmental behaviours such as recycling (Cheung et. al, 1999), riparian zone management (Fielding et al., 2005), composting (Taylor and Todd, 1995), and water conservation (Lynne et al., 1995).

The TPB proposes that the immediate determinant of behaviour is the individual's intention to perform, or not to perform that behaviour. Behavioural intentions are in turn, influenced by three factors: (i) the attitude towards the behaviour, which refers to the individual's favourable or unfavourable evaluation of performing the behaviour; (ii) the subjective norm, which is a social factor referring to the perceived social pressure to perform or not to perform the behaviour; and (iii) the degree of perceived control over the behaviour, which refers to the perceived ease or difficulty of performing the behaviour. To the extent that individuals hold positive attitudes toward the behaviour, think that there is normative support for performing the behaviour, and perceive that they can easily perform the behaviour, they should have strong intentions to perform the behaviour (Ajzen, 1991).

Moreover, an important aspect of the TPB is that it goes beyond merely identifying the direct determinants of intentions and behaviour. The theory also proposes that beliefs about a particular behaviour provide the cognitive foundation from which attitudes, perceived social norms, and perceptions of control are assumed to follow. According to the theory, a person's 
attitude is formed via an expectancy-value analysis, whereby his/her beliefs that the behaviour will be associated with an outcome (behavioural beliefs) are weighted by an evaluation of those outcomes (outcome evaluations). Perceptions of social pressure are thought to be a function of how much one perceives other referents think they should perform the behaviour (normative beliefs) weighted by one's motivation to comply with the referents (motivation to comply).

Finally, perceptions of control are proposed to follow from beliefs about the factors that facilitate or act as barriers to perform the behaviour (control beliefs) weighted by the expected impact that these factors would have if they were to be present (control belief power).

The TPB is especially applicable to behaviours that are not entirely under personal control, and it encompasses the relatively thoughtful process involved in considering personal costs and benefits of engaging in various kinds of behaviours (Petty et al., 1991). This study utilised the TPB theoretical framework because the behaviour of 'paying water bills promptly' is not entirely under the control of the customer. It can be influenced by external factors such as irregular bill delivery (or non-billing), as well as personal factors such as lack of money and time. Figure 1 shows a schematic diagram of the research model as derived from the theory of planned behaviour.

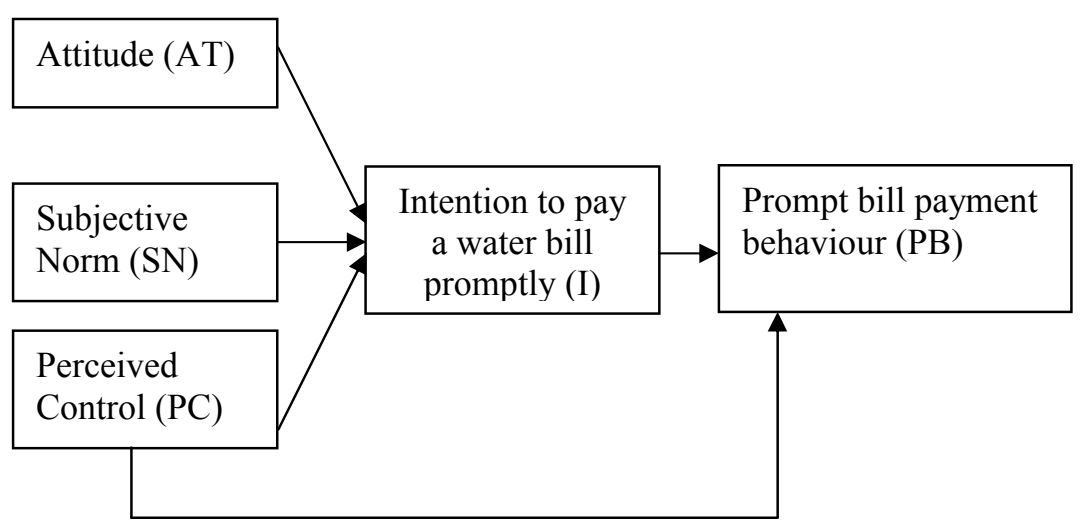

Fig 1: Research model based on the theory of planned behaviour 
In this research model, prompt bill payment behaviour $(\mathrm{PB})$ is defined as the action of paying an outstanding water bill at the utility office within 15 days of receiving the bill. The use of the 15-day window is consistent with the service agreement terms used by the service providers in all the study towns. The intention to perform this behaviour herein referred to as intention to pay a water bill promptly (I) is defined as the perceived likelihood that a customer will pay his/her water bill within 15 days of receiving the bill. The three variables of attitude (AT), subjective norms (SN) and perceived control (PC) are predicted to have a positive direct influence on intentions. In addition, perceived control and intentions are expected to predict prompt bill payment behaviour, in line with the argument that however strongly held the implementation of an intention into action is at least partially influenced by personal and environmental barriers, whether real or perceived (Ajzen, 1991). Finally, behavioural, normative and control beliefs with respect to the behaviour are expected to provide the underlying cognitive foundation for attitudes, subjective norms and perceived control respectively.

\section{RESEARCH DESIGN AND METHODS}

The primary question addressed in this study is: what factors are critically important for motivating customer decisions about paying for water services promptly? In order to answer this question comprehensively, the study utilised the theory of planned behaviour (TPB) discussed above, as a theoretical base. Based on this framework, the primary research question was further broken down into three secondary questions as follows:

- Do attitudes, subjective norms, and perceived control with respect to paying water bills promptly influence customer intentions to actually engage in this behaviour?

- What do utility customers believe to be the benefits, sacrifices, facilitating factors and barriers to paying their water bills promptly? 
- Do expressed intentions to pay water bills promptly translate into actual prompt bill payment behaviour?

To answer these questions, both qualitative and quantitative approaches were utilised. The research setting was eight small urban centres (towns) in Uganda, with populations in the range of 5000 to 25000 inhabitants. The study towns were randomly selected from a sampling frame of 32 towns with piped water services. Water services in Uganda's small urban centres are managed by local private operators under management contracts with the local government water authority. Services in larger urban centres are provided by National Water and Sewerage Corporation (NWSC), the national utility. The sampling frame did not include the larger towns served by NWSC.

The strategy of inquiry was a two-phase sequential approach. The first phase involved collection of qualitative data through focus group discussions in order to explore and generate themes relating to customer beliefs with respect to paying water bills promptly. Then, based on these themes a quantitative measurement instrument was developed and administered in the second phase through a cross-sectional survey of 631 registered domestic customers, which were randomly selected from the customer databases of the utilities involved.

The first phase was conducted during the period between $25^{\text {th }}$ November and $12^{\text {th }}$ December 2005, in five of the eight sample towns (Mugabi et. al, 2007). One focus group discussion was conducted with selected customers in each town, making a total of five discussions with a total of 60 participants. The discussions were relatively structured with high moderator involvement. A set of open-ended questions were used to guide discussions about (i) the benefits and sacrifices associated with paying water bills promptly; (ii) whether there are individuals or groups who would approve or disapprove of the behaviour; and (iii) facilitating factors or barriers to prompt bill payment. The most frequently cited benefits/sacrifices were retained for inclusion in the main questionnaire as a measure of behavioural beliefs. 
Similarly, the most frequently cited referents were used to measure normative beliefs, and the most cited barriers/facilitators were used to assess control beliefs.

The second phase involved the development of a quantitative research instrument which was administered through a cross-sectional survey to obtain data on the key predictor variables specified by the TPB framework. Consistent with Francis et al (2004), the variables of attitude, subjective norms and perceived control were measured both directly (based on their conceptual definitions) and indirectly using the associated behavioural, normative and control beliefs as elicited in the first phase. The process of developing a measurement instrument proceeded as follows:

- A literature review was conducted to enable the development of operational definitions of the constructs, design the response scale format and generate questionnaire items.

- A draft questionnaire was produced based on the literature review and information obtained in the focus group discussions conducted in the first phase. Formatting guidelines suggested by Babbie (1990) and Bourque and Fielder (2003) were generally followed.

- The first draft of the questionnaire underwent a process of multiple pre-testing and piloting in line with social science research practice (Babbie, 1990; Neuman, 1994).

- On the basis of the pre-test and pilot study results, the questionnaire was further refined before it was ready to be administered.

As a result of this process, a questionnaire with Likert-type closed answers was developed. The questionnaire had 69 items in total. Intention was measured directly using a multi-item scale designed to capture overall intentions, as well as desires (e.g. 'I want to pay my next water bill within 15 days of receiving it') and self-predictions (e.g. 'how likely is it that you will pay your next water bill within 15 days of receiving it'). 
Attitude was measured directly using a semantic differential scale. The scale made use of bipolar adjectives that are evaluative in nature, such as good-bad, fair-unfair, harmfulbeneficial (Ajzen, 2002b). An indirect (belief-based) measure of attitude was also obtained via an expectancy-value approach, whereby the perceived likelihood $(+1$ extremely unlikely to +5 extremely likely) that the behaviour will be associated with certain outcomes (benefits/sacrifices) was weighted by customer evaluation of these outcomes in terms of how good or bad, important or unimportant, necessary or unnecessary they are to the customer.

Subjective norms were measured directly using a combination of items that captured perceptions about what important others think the person should do, and perceptions about whether important "others" themselves actually perform the behaviour in question (Ajzen, 2002b). Similar to attitudes, a belief-based measure of subjective norms was obtained by assessing how likely (-2 extremely unlikely, +2 extremely likely) respondents perceive other referents would want them to perform the target behaviour, weighted by their motivation to comply with these referents - i.e. how much they cared (1 not at all, 5 very much) about doing things that these referents would be happy with. The referents groups/individuals identified in the elicitation study included: (i) neighbours; (ii) family members; (iii) water service provider (private operator); and (iv) water vendors

Finally, a direct measure of perceived control was obtained using items that captured: (i) people's confidence that they are capable of performing the behaviour; (ii) perceived difficulty of performing the behaviour or the likelihood that the participant could do it; and (iii) the degree of control a person has over performance of the behaviour, i.e. whether performance of the behaviour is or is not up to them (Ajzen, 2002a). A belief-based measure of this construct was obtained by assessing how often $(+1$ never to +5 always $)$ customers thought they would encounter various facilitating factors/barriers to prompt bill payment as identified in during focus group discussions, weighted by the expected impact that these factors would have if they were to present. 
The process of questionnaire administration commenced on Thursday, $9^{\text {th }}$ February 2006 for most of the study towns, while for others, administration commenced on the weekend of $10^{\text {th }}$ February 2006. Two modes of administration were used: unsupervised self-administration for respondents who were literate and who claimed they understood all contents of the questionnaire; and supervised face-to-face administration by trained interviewers for respondents who were illiterate and/or who claimed they did not understand some /all of the contents of the questionnaire. Use of two methods of questionnaire administration raised the response rate considerably. Out of a net sample size of 505 questionnaires that were actually delivered 490 usable questionnaires were returned, giving a response rate of 97 percent.

Finally, data for prompt bill payment behaviour (PB), the main dependent variable, was obtained using a specially designed monitoring form. The form was designed to monitor customer response to the water bill for the end of February 2006 following questionnaire administration. The objective was to obtain the proportion of total debt paid within the 15day window. Only those customers who had responded to the questionnaire were monitored. However, out of a total 490 respondents who participated in the survey, 41 entries for prompt bill payment behaviour were either incomplete or suspected to be erroneous and were omitted altogether.

\section{RESULTS AND DISCUSSION}

\subsection{Psychometric tests}

In accordance with Ajzen's (2002b) recommendation, direct measures of the four main independent variables (i.e. attitude, subjective norm, perceived control and intention) were checked for acceptable psychometric qualities - i.e. internal consistency reliability and validity. Internal consistency reliability was assessed using Cronbach's coefficient alpha (Pedhazur and Schmelkin, 1991), the results of which are shown in Table 1. The results 
displayed in Table 1 show that each scale had acceptable to good internal reliability (Kline, 1999; Francis et al., 2004).

Table 1: Reliability analysis for attitude, subjective norm, perceived control and intention scales

\begin{tabular}{lcccc}
\hline Scale & Valid cases (N) & Final scale items & Cronbach's alpha & $\begin{array}{l}\text { Item-to-total correlations } \\
\text { (range) }\end{array}$ \\
\hline Attitude & 485 & 6 & .84 & $.45-.72$ \\
$\begin{array}{l}\text { Subjective } \\
\text { norm }\end{array}$ & 483 & 4 & .65 & $.38-.49$ \\
$\begin{array}{l}\text { Perceived } \\
\text { control }\end{array}$ & 482 & 5 & .79 & $.39-.67$ \\
\begin{tabular}{l} 
Intention \\
\hline
\end{tabular} & 478 & 5 & .77 & $.43-.65$ \\
\hline
\end{tabular}

Construct validity was established through exploratory factor analysis. The objective was to define the internal structure of the set of items and assess whether they measured what they were intended to measure (Pett et al., 2003). Using the principal-component method, the scales were factor analysed, and the resultant factor matrices subjected to orthogonal rotation (varimax method) in order to produce simple interpretable structures (Pedhazur and Schmelkin, 1991; Nunnally and Bernstein, 1994; Tabachnick and Fidell, 2001).

Consequently, factor analysis of items intended to measure attitude, subjective norm and perceived control yielded a three factor structure that explained more than 50 percent of the variance, implying good scale validity (Pedhazur and Schmelkin, 1991). Similarly, all items on the intention scale clustered onto one factor accounting for 54 percent of the total variance in intention items, thus providing evidence of scale validity.

\subsection{Determinants of intentions to pay water bills promptly}

To examine the relative importance and explanatory power of the three hypothesised predictors of intentions, a linear regression model was estimated. The regression model was specified as follows: 
$\mathrm{I}=\alpha+\beta_{1} \mathrm{AT}+\beta_{2} \mathrm{SN}+\beta_{3} \mathrm{PC}+\varepsilon$

where I is intention to pay water bill promptly; AT is attitude towards paying water bill promptly; $\mathrm{SN}$ is subjective norm; $\mathrm{PC}$ is perceived control; $\alpha$ is the regression constant and $\varepsilon$ is the residual term.

The null hypothesis $\left(\mathrm{H}_{0}\right)$ tested for the above model is $\mathrm{H}_{0}: \beta_{1}=\beta_{2}=\beta_{3}=0$, where $\beta_{1}, \beta_{2}, \beta_{3}$ are the standardised regression coefficients. The alternative hypothesis for the model is that at least one of the regression coefficients is not equal to zero. The results of the linear regression analysis are summarised in Table 2.

Table 2: Summary of results for linear regression analysis with "intention" as the outcome variable and attitude, subjective norm and perceived control as the predictors

\begin{tabular}{|c|c|c|c|c|c|c|c|}
\hline \multirow[t]{2}{*}{ Model } & \multirow[t]{2}{*}{$\begin{array}{l}\text { Unstandardised } \\
\text { coefficients }\end{array}$} & \multirow[t]{2}{*}{$\begin{array}{l}\text { Standard } \\
\text { error }\end{array}$} & \multirow{2}{*}{$\begin{array}{l}\text { Standardised } \\
\text { coefficients } \\
\text { (ß) }\end{array}$} & \multirow[t]{2}{*}{$\mathrm{t}$ - ratio } & \multicolumn{2}{|c|}{$\begin{array}{l}95 \% \mathrm{CI} \text { for } \\
\text { beta coefficients }\end{array}$} & \multirow{2}{*}{$\begin{array}{c}\text { Semi- } \\
\text { partial } \\
\text { correlations }\end{array}$} \\
\hline & & & & & Lower & Upper & \\
\hline Constant & 0.16 & 0.16 & & & & & \\
\hline Attitude & 0.29 & 0.04 & 0.24 & $7.04 * * *$ & 0.21 & 0.37 & .208 \\
\hline $\begin{array}{l}\text { Subjective } \\
\text { norm }\end{array}$ & 0.15 & 0.03 & 0.16 & $4.81 * * *$ & 0.09 & 0.22 & .142 \\
\hline $\begin{array}{l}\text { Perceived } \\
\text { control }\end{array}$ & 0.52 & 0.03 & 0.55 & $15.52 * * *$ & 0.46 & .59 & .458 \\
\hline
\end{tabular}

Model summary: $\mathrm{R}^{2}=.611$; adjusted $\mathrm{R}^{2}=.609 ; \mathrm{F}=234.29 * * * ; \mathrm{N}=451 \quad * * *$ Significant at $\mathrm{p}<.001$

The results displayed in Table 2 show that all the three predictor variables of attitude $(\mathrm{t}(447)$ $=7.04, \mathrm{p}<.001)$, subjective norms $(\mathrm{t}(447)=4.81, \mathrm{p}<.001)$ and perceived control $(\mathrm{t}(447)=$ $15.52, \mathrm{p}<.001)$ are very highly significantly related to intentions, and hence the null hypothesis that $\mathrm{H}_{0}: \beta_{1}=\beta_{2}=\beta_{3}=0$ is rejected at $\mathrm{p}<.001$. Subjective norm has the smallest Beta coefficient $\left(\beta_{2}=.163, \mathrm{t}=4.8\right)$, and perceived control has the largest $\left(\beta_{3}=.550, \mathrm{t}=15.52\right)$, implying that subjective norm is the least important and perceived control the most important predictor. 
To check whether the model fits the data well, outliers and influential cases were examined using an elaborate procedure suggested by Field (2005). There was no evidence of influential cases within the data, hence suggesting a fairly accurate model. Moreover, tests for the assumptions of linear regression revealed no violations, suggesting that these results can be used to make inferences beyond the sample of data collected.

To uncover the beliefs underlying each of the above predictors, a series of correlation analyses was performed between direct and belief-based measures of attitude, subjective norm and perceived control. Due to space limitations, only the results for perceived control - the most important predictor - are presented in Table 3. Out of a total of 10 control beliefs elicited, 8 have statistically significant (at $\mathrm{p}<.05$ and $\mathrm{p}<.01$ ) associations with perceived control. For control beliefs considered barriers to prompt bill payment (i.e. high water bill, service interruptions, mistakes in meter readings, increase in water consumption, unanticipated circumstances, coloured/unclear water and financial difficulties), the correlation coefficients although small in magnitude $(r<.3)$, have the expected negative signs, implying that the higher the perceived frequency of occurrence of these barriers, the lower the perceived control. 
For those control factors considered facilitators, only reminder visits had a significant positive correlation $(\mathrm{r}=.23, \mathrm{p}<.001)$ with perceived control, implying that those customers who regularly receive reminder visits or notices from the utility, reminding them of unpaid bills, are more likely to perceive more control over paying water bills promptly. This could be because a reminder visit or notice creates an opportunity for the customer, and increases their sense of personal agency to respond.

However, on the basis of significant correlation coefficients between control belief power and perceived control, it appears that only three out of the eight control beliefs (i.e. service interruptions, unanticipated circumstances, and financial difficulties) have the power to influence payment decisions. Given that all three are barriers, it would appear that addressing barriers to prompt bill payment is more important than putting in place facilitators such as reminder visits or notices.

Table 3: Correlation of control belief, control belief power with perceived control

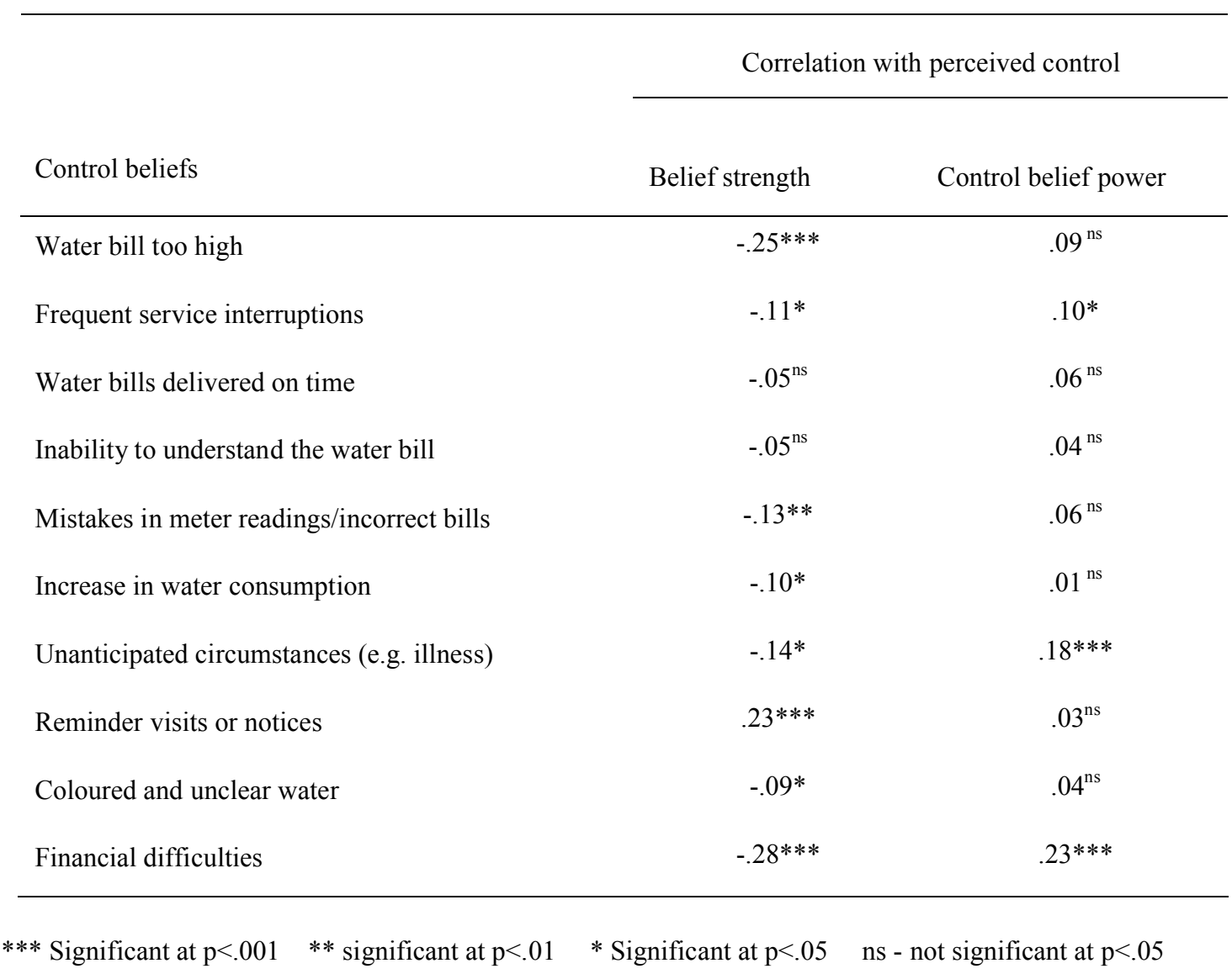


With the exception of unanticipated circumstances and financial difficulties, the rest of the factors perceived to impede prompt bill payment, relate to service delivery issues that are within the full control of the water utility. This observation suggests that opportunities exist for water utilities to influence customer decisions. Of particular importance to utility managers is the finding that frequent service interruptions have the power to influence customer response to bills. This finding seems to confirm Addo-Yobo et al's (2006) claim that supplying water at suitable times and ensuring a reliable service is an effective means of translating customer's expressed willingness to pay into actual paying behaviour.

Moreover, although customers may experience financial difficulties or encounter unanticipated circumstances (such as illness, death of family member) that place extra demands on their household budgets, making it more difficult for them to respond quickly to water bills, such a condition however, does not necessarily mean a chronic lack of ability to pay. Rather, it may reflect situations where a monthly bill exceeds household cash flow. Given the low-incomes of most customers in small towns, this finding has important implications for the design of appropriate payment arrangements.

The foregoing analysis on the cognitive foundation for perceived control was extended to attitudes and subjective norms - the other significant predictors of intentions ${ }^{\ddagger}$. Results (Mugabi, 2007) showed that attitudes towards prompt payment were informed by perceptions of benefits and sacrifices associated with the behaviour, while social pressure was perceived to come from family members, neighbours and the utility itself. Perceived benefits/sacrifices included: the belief that paying the water bill promptly would (i) result in being served by well equipped and motivated staff; (ii) result in being served by a properly maintained water system; (iii) result in foregoing other household needs; (iv) help to avoid accumulated bills; and (v) ensure that the service is not disconnected. The belief that 'paying the bill in time ensures that water is not disconnected' had the strongest positive association

\footnotetext{
Correlation analysis results not reported due to space limitation
} 
with attitude - which is not entirely surprising given the vigilance of the utilities in disconnecting non-paying customers.

\subsection{Predictors of prompt bill payment behaviour}

Logistic regression analysis was used to examine the extent to which intentions and perceived control are predictive of behaviour. This analytical technique was deemed the most appropriate because of the nature of the outcome variable. Data for prompt bill payment behaviour data exhibited little variation between the zero and 100 percent limits. This means that using linear regression techniques would have almost certainly led to a poor model because the assumption of normally distributed residuals is difficult to sustain with a skewed outcome variable (Miles and Shevlin, 2001; Field, 2005).

Therefore, consistent with this analytical technique, prompt bill payment behaviour - the outcome variable - was transformed into a dichotomous variable as illustrated in Table 4 . In order to provide a more complete analysis, two dichotomous variables are extracted. The first variable categorises the data into those customers who fully paid their water bill within the 15-day window (58 cases) and those who did not pay (243 cases). The second variable is a dichotomy of those who paid half or more (151 cases), and those who did not pay or paid less than half their water bill within the 15-day window (278 cases).

For both variables, the numerical coding (i.e. 1 and 0 ) is arbitrary, and logistic regression does not attempt to predict these arbitrary values. What is important for this analysis is whether the classification of cases into one or the other of the categories of the outcome variable can be predicted by the predictor variable. Thus, the analysis is concerned with predicting the probability that a case will be classified into one as opposed to the other of the two categories of the outcome variable. 
Table 4: Dichotomous variables extracted from prompt bill payment behaviour (PB) data

\begin{tabular}{lcccc}
\hline & \multicolumn{2}{c}{ PB dichotomy 1 } & \multicolumn{2}{c}{ PB dichotomy 2 } \\
\cline { 2 - 5 } & Paid fully (100\%) & Did not pay $(0 \%)$ & $\begin{array}{l}\text { Paid half or } \\
\text { more }(\geq 50 \%)\end{array}$ & $\begin{array}{l}\text { Did not pay }(0 \%) \text { or } \\
\text { paid less than half }(<50 \%)\end{array}$ \\
\hline Valid cases (N) & 58 & 243 & 151 & 278 \\
Variable coding & 1 & 0 & 1 & 0 \\
\hline
\end{tabular}

Based on these dichotomies, two regression models were specified. The first model is concerned with predicting the probability that a customer belongs to the category of those who fully paid their water bill within the 15-day window, given their scores on the predictor variables of intentions and perceived control. This model (hereinafter referred to as logistic regression model 1 or simply, LRM-1) is specified as follows:

LRM-1: $P$ (paid fully) $=\frac{1}{\left.1+\mathrm{e}^{-\left(\alpha+\beta_{1} \mathbf{I}+\beta_{2} \mathbf{P C}\right.}+\varepsilon\right)}$

where: $\mathrm{P}$ (paid fully) - is the probability that a customer belongs to the category of those who fully paid their water bill within the 15-day window; I is intention to pay water bill promptly; $\mathrm{PC}$ is perceived control; e is the base of natural logarithms; $\varepsilon$ and $\alpha$ are the error and constant terms respectively

The second model is concerned with predicting the probability that a customer belongs to the category of those who paid 50 percent or more of their water within the 15-day window, given their scores on the predictor variables of intentions and perceived control. This model (hereinafter referred to as logistic regression model 2 or simply, LRM-2) is specified as follows:

LRM-2: $\quad \mathrm{P}($ paid half or more $)=\frac{1}{\left.1+\mathrm{e}^{-\left(\alpha+\beta_{1} \mathbf{I}+\beta_{2} \mathbf{P C}\right.}+\varepsilon\right)}$ 


\begin{abstract}
where: P (paid half or more) - is the probability that a customer belongs to the category of those who paid 50 percent or more of their water within the 15-day window; I is intention; PC is perceived control; e is the base of natural logarithms; $\varepsilon$ and $\alpha$ are the error and constant terms respectively
\end{abstract}

For both LRM-1 and LRM-2, the null hypothesis $\left(\mathrm{H}_{0}\right)$ tested is $\mathrm{H}_{0}: \beta_{1}=\beta_{2}=0$, where $\beta_{1}$ and $\beta_{2}$ are the logistic regression coefficients. The alternative hypothesis is that at least one of the regression coefficients is not equal to zero. Estimation results for both models are presented in Table 5.

From Table 5, the model chi-square for LRM-1, $\chi^{2}(1)=7.85,(\mathrm{p}=.005)$ and LRM-2, $\chi^{2}(2)=$ $10.92(\mathrm{p}=.004)$ are statistically significant at $\mathrm{p}<.05$, implying that it is unlikely that chance effects alone would predict the outcome variable as well as the models.

Table 5: Summary of logistic regression results

\begin{tabular}{|c|c|c|c|c|c|c|c|}
\hline \multirow[t]{2}{*}{ Model } & \multirow[t]{2}{*}{ Model $\chi^{2}$ (p-value) } & & \multicolumn{2}{|c|}{$\begin{array}{l}\text { Logistic regression } \\
\text { coefficients }\end{array}$} & \multicolumn{3}{|c|}{$95 \%$ CI for $\exp \beta$} \\
\hline & & & $\beta$ & $\begin{array}{l}\text { Standard } \\
\text { error }\end{array}$ & Lower & $\exp \beta$ & upper \\
\hline & & Constant & -4.70 & 1.10 & & & \\
\hline \multirow[t]{3}{*}{ LRM-1 } & $7.85 * *(p=.005)$ & Intention & $0.72 *$ & 0.27 & 1.22 & 2.06 & 3.48 \\
\hline & & $\begin{array}{l}\text { Perceived } \\
\text { control }\end{array}$ & $0.37 \mathrm{~ns}$ & 0.38 & 0.69 & 1.45 & 3.06 \\
\hline & & Constant & -3.05 & & & & \\
\hline \multirow[t]{2}{*}{ LRM-2 } & $10.92 * *(p=.004)$ & Intention & $0.54 *$ & 0.27 & 1.01 & 1.72 & 2.91 \\
\hline & & $\begin{array}{l}\text { Perceived } \\
\text { control }\end{array}$ & $0.07 \mathrm{~ns}$ & 0.26 & 0.65 & 1.07 & 1.77 \\
\hline
\end{tabular}

LRM-1: Hosmer and Lemeshow $\chi^{2}=8.52^{\mathrm{ns}}(\mathrm{p}=.38)$;

LRM-2: Hosmer and Lemeshow $\chi^{2}=5.88^{\mathrm{ns}}(\mathrm{p}=.66)$;

$* *$ Significant at $\mathrm{p}<.01 ; \quad *$ significant at $\mathrm{p}<.05 ;$ ns - not significant at $\mathrm{p}<.05$ 
To further test the explanatory power of models, the Hosmer and Lemeshow (H-L) goodness-of-fit test (Hosmer and Lemeshow, 2000) was applied. This test compares the amount of information gained by constructing the model to the amount of information available without the model (the null case). Thus, a non-significant test would indicate a model that does not differ significantly from the observed data. For both LRM-1 and LRM2, the H-L goodness-of-fit test statistic was non significant at $\mathrm{p}<.05$, implying that estimates from both models fit the data to an acceptable level (Field, 2005).

Furthermore, for both models, the coefficient estimates for intentions are statistically significant $(p<.05)$ while those of perceived control are non-significant $(p<.05)$. This implies that only intention makes a statistically significant contribution to the prediction of prompt bill payment behaviour. Although perceived control displays the correct direction of relationship, it does not make a significant direct contribution to prompt bill payment behaviour.

The non-significant result for perceived control is however not uncommon in studies using the TPB framework (Godin and Kok, 1996; Notani, 1998; Armitage and Conner, 2001). Empirical studies (e.g. Sheeran et al., 1999; Conner, 2000; Sheeran et al., 2003) have shown that perceived control can only serve as an independent predictor of behaviour to the extent that it is stable, accurate and reflects actual control. In this study, it appears perceived control, although exhibiting good temporal stability (test-retest $r=.7$ ), did not really reflect actual control, hence the poor relationship with behaviour. This however does not mean that the perceived control variable is not important in changing payment behaviour. On the contrary, according to the semi-partial correlation coefficients presented in Table 2, perceived control uniquely explains the largest percentage ( 21 percent) of variance in intentions to pay, suggesting that most of its contribution to prompt bill payment behaviour is made through the intention variable. 
To illustrate the illustrate the significance of the relationship between intentions and behavior, probability plots for both models LRM-1 and LRM-2 were produced as shown in Figure 2 . These graphs were plotted using probability values obtained by substituting the estimated model parameters into model equations for LRM-1 and LRM-2, for different values of the intention score (including the mean score). From Figure 2, it can be noted that a respondent who scored 5 (the highest score) on the intention scale has a 25 percent chance of actually paying his or her water bill fully and a 41 percent of paying half or more within the 15 days. Corresponding probability values, with the intention score set at the mean level, are 13 percent and 28 percent respectively. For respondents with the lowest intention score, the probability of paying is less than 10 percent, which is low, but nevertheless far from indicating that these respondents never pay their bill promptly.

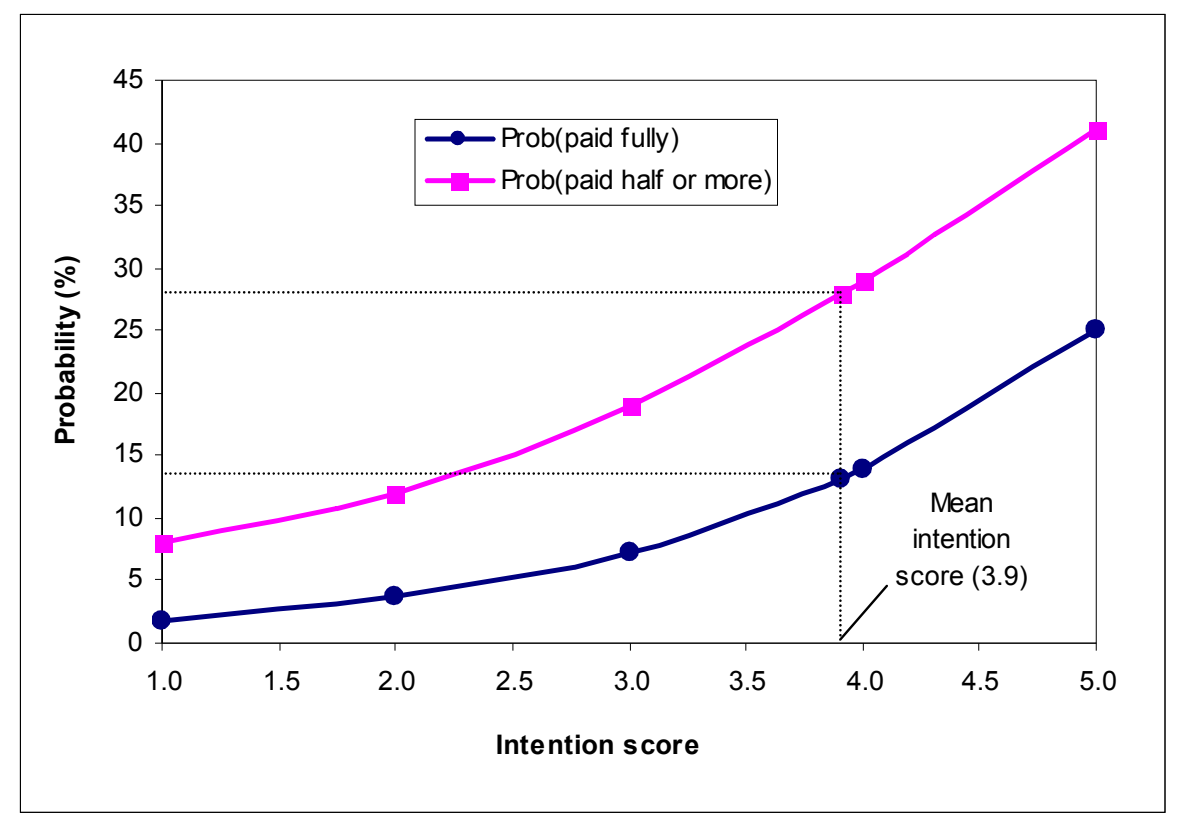

Fig 2: Probability plot for LRM-1 and LRM-2

The figure also shows that for the same intention level, the probability of paying half or more is always higher than the probability of paying the entire bill within the 15 -day window - a result that has implication for the design of appropriate and flexible payment systems. 


\section{RESEARCH IMPLICATIONS}

The findings of this research have several implications for improving cost recovery in small urban water utilities in low- income countries. Firstly, the results suggest that frequent service interruptions negatively influence customer decisions relating to prompt payment of water bills. Therefore, in the current context, it appears that ensuring reliability of supply i.e. consistency and adequacy of supply as per the promised service level - is one of the critical actions that managers can take to promote prompt bill payment. This however might require additional investment to increase production levels, where there is a substantial supply deficit.

Secondly, managers need to address customer perceived barriers to prompt bill payment by minimising errors and mistakes in billing, as well as reducing wastage and losses incurred through tap leakages and faulty meters. Findings from focus group discussions revealed that customers often receive high water bills that reflect malfunctioning installations (such as taps and meters) due to infrequent or poor maintenance. In most cases, leakage and wastage is reported as the primary cause of high water bills, leading to non-payment. Understandably, customers would be unwilling to pay for water they did not consume, and therefore, utilities need to be proactive. Initiatives could include more frequent meter readings, increasing customer awareness, facilitating checks and repairs and carrying out demand management and water conservation programs.

Thirdly, given the low disposable incomes of customers in small urban centres, utilities need to design flexible billing and payment arrangements to help customers pay their bills when they have the money on hand rather than on a monthly basis, as is the case in most countries. This study has provided some evidence to suggest that customers may experience financial difficulties which make it difficult for them to pay large monthly bills. Because most customers have irregular incomes, payment difficulties may be due to cash flow problems, as opposed to 
an absolute inability to pay. Utilities therefore need to adapt their billing systems, allowing more payment flexibility in a manner that better suits household budgeting and expenditure.

Fourthly, the findings of this study suggest that the likelihood of not being disconnected plays a big role in shaping positive attitudes towards paying water bills in time. In the current context, it appears that the diligence of utilities in disconnecting non-paying customers is having an influence. This strategy signals to customers the consequences of not paying water bills in time, and therefore, avoiding disconnection becomes the main perceived benefit of paying bills in time. However, although the disconnection strategy may work well in shaping positive customer attitudes, it can be counterproductive when implemented indiscriminately without due consideration to the particular circumstances of customers. For instance, it would be particularly inappropriate to disconnect customers who are facing short-term payment difficulties. Nor would the disconnection of service in these circumstances protect the utility against any future loss of revenue. Instead, it has the potential to affect customer relations and hence satisfaction levels, which might be damaging in the long term.

In short, utilities may need to review their all too familiar “one-size-fits-all' strategy to dealing with customers in arrears, and instead adopt a marketing approach grounded on good knowledge of customer circumstances. For instance, utilities could segment customers into categories based on how quickly they react to water bills. This would enable managers to design targeted strategies for debt management and recovery. Those customers considered to be high risk would be flagged for personal follow-up immediately a payment is missed; those deemed low-risk would be sent a reminder letter and vulnerable customers, who are struggling to pay, can be offered additional help and advice. Adopting such a proactive customer-focused strategy has potential not only to transform revenue collection but also to increase customer satisfaction. Small urban water utilities need to take advantage of their relatively small number of customers by adopting a customised approach to debt management and recovery. 
Finally, the results of the present study have clear implications for the design of publicity and education programmes that aim to encourage prompt bill payment behaviour. The wide range of behavioural, normative and control beliefs identified in the study could be used to develop publicity messages aimed at bringing about desirable changes in customer attitudes, subjective norms and perceptions of control respectively. In addition, other ways (apart from publicity and education) of bringing about changes in attitudes could be sought. For instance, it might be difficult through publicity alone to alter the belief that "paying a water bill in time will result in foregoing other household needs". Altering this belief might warrant the need for changes in the billing schedules - e.g. allowing several smaller bill payments against a single bill. Once such a payment arrangement is in place, publicity could then be used to encourage customers to use it.

Furthermore, utilities need to explore incentive mechanisms in the form of discounts or vouchers for prompt and regular payment. Such mechanisms serve to demonstrate to customers that the utility strongly desires to receive payments in time, thereby increasing the normative pressure on customers to respond quickly to bills.

\section{CONCLUSION}

This paper has provided some insights on what motivates water utility customers when it comes to paying their water bills promptly. Using empirical data from Uganda, the paper has provided evidence in support of the theory of planned behaviour, that customer attitude towards prompt payment, perceived ease or difficulty of paying on time (perceived control), as well as social pressure, strongly influence intentions to pay, which in turn directly affects actual prompt bill payment behaviour. Thus, it follows that attitudes, perceptions of social pressure and control are important factors for motivating customer decisions about paying for water services promptly. However, perceptions of control (i.e. the ease or difficulty of engaging in the behaviour) are far more important than attitude towards the behaviour or the perception of social pressure. 
Moreover, perceived control was found to reflect both internal and external impediments to prompt bill payment. The findings also suggest that addressing perceived barriers to prompt bill payment is more important than putting in place facilitators. Some of the perceived barriers identified include: i) high water bills; (ii) frequent service interruptions; (iii) mistakes in meter readings, (iv) increase in water consumption, (v) unanticipated circumstances that place extra demands on household budget; (vi) coloured or unclear water; and (vii) financial difficulties. With the exception of unanticipated circumstances and financial difficulties, the rest of the factors perceived to impede prompt bill payment, relate to service delivery issues that are within the full control of the water utility. Therefore, opportunities exist for water utilities to motivate customer decisions about prompt payment of water bills, and this paper has identified possible ways through which utilities can achieve this goal.

Some limitations of this study however should be noted. Firstly, the cross-sectional design adopted means that the study could only prove relationships between variables but not causation. However, while it is true that a correlation between two variables does not establish causation, it is a pre-requisite for establishing a causal relationship. Thus, if there is no correlation, a researcher is confident that there is not a causal relationship. Eliminating variables as causes is of as much scientific importance as locating causes. Secondly, owing to the low literacy levels in the study setting, the survey questionnaire had to be interpreted to a portion of the sample that indicated preference for this method of administration. Interpreting questionnaire items in local languages could have resulted in loss of precision in the meaning of constructs, due to lack of corresponding terminologies. It is also likely that some respondents who opted to self-administer the questionnaire might not have understood all the questions. Nonetheless, the results of the psychometric analysis showed that respondents' answers had good internal consistency.

In light of the above limitations, further research in this area could take on a number of directions. First, as noted above, the cross-sectional design of the current study limited the 
author to making only correlational inferences. It would be more beneficial to water utility managers if causal research was carried out using a longitudinal research design. Moreover, there is a possibility that over time, customers develop a habit of either paying water bills late or in time. Such habits can only be examined adequately using a longitudinal research design.

Secondly, further research could use a similar conceptual framework, but focus on nondomestic customers, such as institutions (e.g. schools, health centres), and small-scale industries. Such research could examine whether the factors that influence the payment behaviour of domestic consumers differ from those that affect non-domestic customers. Similarly, since consumer behaviour is bound to vary in different contexts, further research should be carried out in a different context (e.g. in other low-income countries or in larger urban centres) in order to generalise the findings.

Finally, although the current research has provided insights into some of the actions and strategies that may be taken to promote prompt bill payment, further research is needed to investigate the methods for effectively changing customer behaviour. Also, any behavioural change intervention designed on the basis of the results of this study should be fully evaluated to determine its effectiveness.

\section{REFERENCES}

Accent Marketing and Research (2003). Paying for water: customer research. London, Report prepared for UK Water Voice and Ofwat.

Addo-Yobo, F. N., Njiru, C. and Sohail, M. (2006). "Determinants of household's intention to pay for improved water services: an application of the Theory of Reasoned Action." Journal of Water Supply: Research and Technology-AQUA 55(6): pp 419-425.

Ajzen, I. (1991). "The Theory of Planned Behaviour." Organisational Behaviour and Human Decision Processes 50(1991): 179-211.

Ajzen, I. (2002a). "Perceived behavioural control, self-efficacy, locus of control, and the Theory of Planned Behaviour." Journal of Applied Social Psychology 32: pp.1-20. 
Ajzen, I. (2002b). Constructing a theory of planned behaviour questionnaire: conceptual and methodological considerations. Amherst, University of Massachusetts, Available at: http://www.people.umass.edu/aizen/pdf/tpb.measurement.pdf: [accessed June 2005].

Ajzen, I. and Fishbein, M. (1980). Understanding attitudes and predicting social behaviour New Jersey, Prentice-Hall, Inc.

Armitage, C. J. and Conner, M. (2001). "The efficacy of the theory of planned behaviour: A meta-analytic review." British Journal of Social Psychology 40: pp. 471-499.

Babbie, E. (1990). Survey research methods, 2nd Edition. Belmont, CA: Wadesworth Publishing Company.

Bandura (1997). Self-efficacy: The exercise of control. New York, Freeman.

Bourque, L. B. and Fielder, E. P. (2003). How to conduct self-administered and mail surveys, 2nd Edition Thousand Oaks, CA, Sage Publications.

Casey, J. F., Kahn, J. R. and Rivas, A. (2006). "Willingness to pay for improved water service in Manaus, Amazonas, Brazil." Ecological Economics 58: 365-372.

Cheung, S. F., Chan, D. K. S. and Wong, Z. S. Y. (1999). "Re-examining the theory of planned behaviour in understanding wastepaper recycling." Environment and Behaviour 31: 587-612.

Cohen, J. (1988). Statistical power analysis for the behavioural sciences, 2nd Edition. New York, Academic Press.

Conner, M. (2000). "Temporal stability as a moderator of relationships in the theory of planned behaviour." British Journal of Social Psychology 39: 469-493.

Cox, D. R. and Snell, D. J. (1989). The analysis of binary data, 2nd edition. London, Chapman \& Hall.

Field, A. (2005). Discovering statistics using SPSS, 2nd edition. London, Sage Publications.

Fielding, K. S., Terry, D. J., Masser, B. M., Bordia, P. and Hogg, M. A. (2005). "Explaining landholder's decisions about riparian zone management: The role of behavioural, normative and control beliefs." Journal of Environmental Management 77(1): 12-21.

Francis, J. J., Eccles, P. M., Johnston, M., Walker, A., Grimshaw, J., Foy, R., Kaner, E. F., Smith, L. and Bonetti, D. (2004a). Constructing questionnaires based on the theory of planned behaviour: a manual for health services researchers. Newcastle, Centre for Health Services Research, University of Newcastle. Available at: http://www.rebeqi.org/ViewFile.aspx?itemID=212 [accessed 12 July 2006].

Godin, G. and Kok, G. (1996). "The theory of planned behaviour: A review of its applications to health-related behaviours." American Journal of Health Promotion 11: 87-98.

Gulyani, S., Talukdar, D. and Kariuki, R. M. (2005). Water for the urban poor: water markets, household demand, and service preferences in Kenya. World Bank Water Supply and Sanitation Sector Board Discussion Paper Series Paper No. 5. Washington, DC, World Bank.

Herbert, A. and Kempson, E. (1995). Water debt and disconnection. London, Policy Studies Institute. 
Hopkins, O. S., Lauria, D. T. and Kolb, A. (2004). "Demand-based planning of rural water systems in developing countries." Journal of Water Resources Planning and Management 130(1): 44-52.

Hosmer, D. W. and Lemeshow, S. (2000). Applied logistic regression, 2nd edition. New York, Wiley.

Jenner, E. A., Watson, P. W. B., Miller, L., Jones, F. and Scott, G. M. (2002). "Explaining hand hygiene practice: an extended application of the theory of planned behaviour." Psychology, Health and Medicine 7(3): 311-326.

Katko, T. (1991). Paying for water in developing countries. Tampere, Tampere University of Technology.

Kayaga, S., Franceys, R. and Sansom, K. (2004). "Bill payment behaviour in urban water services: empirical data from Uganda." Journal of Water Supply: Research and Technology-AQUA 53(2004): 339-349.

Kayaga, S. M. (2002). The influence of customer perceptions of urban utility water services on bill payment behaviour: Findings from Uganda. PhD Thesis, WEDC, Loughborough University.

Kline, P. (1999). The Handbook of psychological testing, 2nd edition. London, Routledge.

Lynne, G. D., Casey, C. F., Hodges, A. and Rahmani, M. (1995). "Conservation technology adoption decisions and the theory of planned behaviour." Journal of Economic Psychology 16: 581-598.

Mugabi, J. (2007). Determinants of customer decisions to pay utility water bills promptly. $\mathrm{PhD}$ Thesis, Loughborough University, UK.

Mugabi, J., Kayaga, S., and Smout, I. (2007): “Why Water Utility Customers Don't Pay their Bills Promptly". Water Utility Management International, 2 (2) pp 17-20

Neuman, W. L. (1994). Social research methods: qualitative and quantitative approaches, 3rd edition. Needham Heights, MA: Allyn and Bacon.

Notani, A. S. (1998). "Moderators of perceived behavioural control's predictiveness in the theory of planned behaviour: A meta-analysis." Journal of Consumer Psychology 7(3): 247-271.

Nunnally, J. and Bernstein (1994). Psychometric theory, 3rd edition. New York, McGrawHill.

Pedhazur, E. J. and Schmelkin, L. P. (1991). Measurement, design and analysis: an integrated approach. Hillsdale, NJ, Lawrence Erlbaum.

Perez-Pineda, F. (1999). Estimating the willingness to pay for water services in developing countries: A case study of the use of a contingent valuation survey in El Salvador, Central America. PhD Thesis, Purdue University.

Pett, M. A., Lackey, N. R. and Sullivan, J. J. (2003). Making sense of factor analysis: The use of factor analysis for instrument development in health care research. Thousand Oaks, Sage Publications, Inc. 
Petty, R., Unnava, R. and Stratham, A. (1991). Theories of attitude change. In: Robertson, T. S. and Kassrjiann, H. H. (eds). Hand book of consumer behaviour, pp. 241-280. London, Prentice-Hall.

Sheeran, P. and Taylor, S. (1999). "Predicting intentions to use condoms: a meta-analysis and comparison of the theories of reasoned action and planned behaviour." Journal of Applied Social Psychology 29: pp. 1624-1675.

Sheeran, P., Trafimow, D. and Armitage, C. J. (2003). "Predicting behaviour from perceived behavioural control: tests of the accuracy assumption of the theory of planned behaviour." British Journal of Social Psychology 42: 393-410.

Tabachnick, B. G. and Fidell, L. S. (2001). Using multivariate statistics, 4th edition. Boston, Allyn \& Bacon.

Taylor, S. and Todd, P. (1995). "An integrated model of waste management behaviour: a test of household recycling and composting intentions." Environment and Behaviour 27: 603-630.

UK Water Industry Research (2004). Water industry debt: socio-economic and demographic effects. London, UK Water Industry Research (UKWIR).

Venkatachalam, L. (2006). "Factors influencing household willingness to pay for drinking water in peri-urban areas: a case study in the Indian context." Water Policy 8: 461473.

Whittington, D., Pattanayak, S. K., Yang, J. C. and Bal Kumar, K. C. (2002). "Household demand for improved piped water services: evidence from Kathmandu, Nepal." Water Policy 4(2002): 531-556.

World Bank Water Demand Research Team (1993). "The demand for water in rural areas: determinants and policy implications." The World Bank Research Observer 8 (1) 4770. 